\title{
SOBRE LA JURISPRUDENCIA COMO TÉCNICA SOCIAL. RESPUESTA A ROBERTO J. VERNENGO
}

1

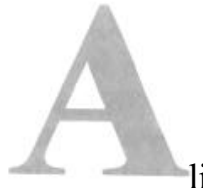

ún a riesgo de incrementar la fatiga que al profesor Vernengo le ocasionan estos temas, no voy a dejar pasar la oportunidad de emitir algunas opiniones sobre sus agudos comentarios a propósito de uno de los problemas abordados en mi libro Introducción al Derecho (Atienza, 1985). El lector, sin duda aún no suficientemente fatigado por la cuestión después de haber leído a Vernengo, no se tomará a mal -supongo- que comience mi exposición mostrando algunas discrepancias -quizás no tan sólo de matiz- con la descripción que Vernengo hace de mis puntos de vista, para pasar después a consideraciones que tienen más que ver con el fondo del asunto: el de la cientificidad o no de la Jurisprudencia. Al final trataré de mostrar sintéticamente cuál es el balance que, en mi opinión, arroja la polémica.

\section{2}

El primer y fundamental punto de discrepancia con Vernengo se refiere a la tesis que él me atribuye, y que yo creo no haber defendido nunca, según la cual la Jurisprudencia, la «ciencia» del Derecho, no sería otra cosa que política. Ya el mismo título puesto a su comentario («Ciencia jurídica o técnica política») apunta a ello, al igual que numerosas afirmaciones que, según entiendo, reflejarían -en opinión de Vernengo- mi punto de vista sobre la cuestión, tales como las siguientes: «Las funciones cumplidas por la dogmática no se agotan en la aséptica construcción de un sistema conceptual, sino en la elaboración de «criterios para la elaboración de las normas vigentes» y de «criterios para el cambio del Derecho». Vale decir: «hacer ciencia jurídica es hacer política...» (Vernengo, 1986). «¿Cómo dudar de que el lenguaje de la ciencia jurídica no sea tan prescriptivo como las normas que dice estudiar y cómo diferenciar el discurso pragmático del político del discurso del jurista que, a la postre, dice lo mismo?» (Ibid.). «Pero si haciendo una generalización imprudente, todas las actividades de los juristas, y su discurso, son considerados aserciones políticas- incurriendo en gran confusión de lenguaje...»(Ibid.)

Ahora bien, la tesis de la politicidad de la Jurisprudencia puede defenderse como una tesis fuerte (la Jurisprudencia es tan sólo una forma de la política) o como una tesis débil (la Jurisprudencia es una actividad impregnada de politicidad, pero la Jurisprudencia no puede reducirse a política). Vernengo me atribuye la primera de las dos tesis, cuando la que yo creo haber defendido es la segunda. El párrafo que sigue, extraído del libro al que él se refiere, bastará, me parece, para justificar lo que digo: «... los juristas marxistas -y no son los únicos- propenden a asumir frente a las normas un punto de vista político. A menudo ven el Derecho vigente como un ins- 
trumento de lucha política. En mi opinión, es inevitable reconocer en la actividad dogmática una dimensión sociológica (...) e igualmente, una dimensión política (...), pero el carácter sociológico y político de la Jurisprudencia tiene también un límite. En otro caso, la dogmática dejaría de ser un mecanismo que facilita el funcionamiento y desarrollo del Derecho velando al mismo tiempo por la seguridad jurídica, es decir, haciendo que los actos de las autoridades y de los ciudadanos en general, o mejor dicho, las consecuencias jurídicas de éstos, resulten relativamente previsibles» (Atienza, 1985, pp. 175-6).

Por otro lado, yo no afirmo tampoco que el lenguaje de la ciencia jurídica sea tan prescriptivo como el del Derecho mismo, sino -algo más matizadamente- que «no parece posible establecer siempre una neta distinción entre las normas -el Derecho positivo- y las proposiciones normativas elaboradas por la ciencia del Derecho» (Atienza, 1985, p. 277). Y al ocuparme tanto de la concepción de Kelsen, como de la de Hart o Bobbio, destaco el propósito que creo encontrar en los tres autores -aunque, en mi opinión, no logrado del todo- de aislar y analizar un tipo de enunciados distintos tanto de las prescripciones (de las normas) como de las simples descripciones, y que deberían servir para caracterizar discursos como el de la dogmática jurídica ( Ibid., pp. 238, 252 y 255).

Debo mostrar también mi disconformidad con alguna otra afirmación de Vernengo, como la siguiente: «Atienza apunta que el carácter mutable del objeto jurídico, su contingencia y la manifiesta inutilidad y falta de actualidad de la actividad del jurista científico, que Kirchmann denuncia, son características que pueden hacerse extensivas a la jurisprudencia pensada como una mera técnica social» (Vernengo, 1986). Pero lo que yo pretendí afirmar -y, según creo, afirmé- no es precisamente eso, sino que «si partimos de la idea de que la Jurisprudencia es una técnica, los argumentos de von Kirchmann se vuelven sencillamente impertinentes» (Atienza, 1985, p. 281), es decir, resultan fuera de lugar, dejan incluso de tener sentido. En particular, yo nunca he sostenido que la Jurisprudencia sea o haya sido una actividad inútil (como parece sugerirlo el párrafo de marras, aunque el propio Vernengo lo «rectifica», en cierto modo, un poco más adelante), sino, muy por el contrario, que «no es difícil mostrar que la dogmática jurídica, considerada globalmente, cumple una función social útil (...). En pocas palabras, la función positiva de la dogmática podría explicarse así: un sistema jurídico que careciera de elaboración dogmática estaría en disposición de resolver muchos menos problemas que el mismo sistema dotado de una dogmática adecuada» (Atienza, 1985, p. 282).

Y dejaré ya esta especie de «memorial de agravios»-que de todas formas hubiera podido ser más extenso- para pasar a ocuparme de la parte de la crítica de Vernengo que considero afecta a mi postura.

\section{3}

La crítica más importante que me dirige Vernengo es que mi tesis de que la Jurisprudencia no es una ciencia, sino una técnica, presupone obviamente una distinción entre ciencia y técnica que no sólo no está desarrollada en mi libro (excepción hecha de una referencia al «conocer por conocer» de 
la ciencia frente al «conocer para actuar» de la técnica que él juzga insostenible) sino que, en su opinión, es imposible de establecer; ello, por otro lado, arruinaría por completo mi tesis desde su propia raíz, ya que «interrogarse sobre si una cierta actividad o un cierto discurso sea ciencia o técnica, implica sustentar una distinción que el pensamiento actual más bien conjuga» (Vernengo, 1986).

Si yo pretendiera defender mi concepción de la dogmática jurídica tal y como aparece formulada en el libro a que se refiere Vernengo, frente a la objeción que acabo de indicar, los argumentos a esgrimir serían, más o menos, del siguiente tenor.

El primero consistiría en negar que haya pretendido presentar el dominio de la ciencia y el de la técnica como absolutamente excluyentes. Vernengo sugiere -o, más que sugiere, afirma- que una tesis fundante de mi concepción es la de que «ciencia (teoría) y técnica (práctica) son dominios excluyentes, tanto vistas como actividades, como vistas como un discurso. Por el contrario, pareciera que lo típico de las ciencias modernas y de las técnicas respetables es el no dar pie a tal dicotomía» (Vernengo, 1986). Pero también aquí habría que decir, una vez más, que una cosa es pensar o postular que ciencia y técnica son realidades distintas y que se deben distinguir, como es mi punto de vista, y otra bastante distinta es considerar que se trata de dominios excluyentes, es decir, considerar que se puede establecer entre ellas una distinción tal que convierta a ambas actividades en realidades que no posean nada en común. En realidad, no me hallo en desacuerdo con las consideraciones que Vernengo hace a propósito de la estrecha interconexión existente entre la ciencia y la técnica pero, en mi opinión, ello no significa que haya que renunciar a diferenciar la una de la otra.

Y el segundo argumento podría formularse así. Aunque no estuvo entre mis propósitos tratar a fondo la cuestión, en mi libro puede encontrarse alguna referencia a la distinción ciencia/técnica, más allá de la que Vernengo considera. Me tomo la libertad de citar de nuevo aquí algunos párrados de aquella obra: «La investigación técnica no trata de explicar un acontecimiento, sino de estudiar cómo se puede producir un determinado resultado, dadas ciertas condiciones; su fin no es propiamente conocer, sino obtener ciertos resultados prácticos valiéndose de ciertos conocimientos. En consecuencia, una regla técnica -por ejemplo, la interpretación que hace la dogmática de un determinado artículo- será más progresiva que otra si consigue obtener más y mejores resultados; en el caso de la dogmática, si permite resolver más problemas jurídicos típicos o permite resolverlos mejor. Naturalmente, la evaluación del progreso técnico choca con dificultades semejantes a las que tenía que afrontar la ciencia. Así, el ejemplo anterior de la dogmática presupone un consenso respecto a cuáles deben considerarse como problemas jurídicos, y cuales son los límites normativos, valorativos, etcétera, dentro de los que debe moverse la actividad de los dogmáticos» (Atienza, 1985, p. 282).

\section{4}

Como no deseo limitar la discusión sobre este problema a lo que pude escribir o dejar de escribir en aquella ocasión, trataré de aprovechar la opor- 
tunidad que me brinda esta polémica con el profesor Vernengo para desarrollar la tesis del carácter esencialmente técnico de la Jurisprudencia, que sigo considerando como una tesis adecuada. Con este propósito, las páginas que siguen las dedicaré a mostrar, en primer lugar, que es posible -y deseable- distinguir la ciencia de la técnica y que es posible trazar una distinción que no los presente como dominios por completo excluyentes; luego señalaré como tal caracterización de la técnica se adecúa bastante bien a lo que es la Jurisprudencia (a lo que los dogmáticos hacen cuando desarrollan la dogmática jurídica); y finalmente indicaré qué consecuencias se derivan de dicha caracterización o, dicho de otra manera, trataré de mostrar que la discusión en torno a la naturaleza (real o posible) de la Jurisprudencia no es estéril.

4.1. En una obra reciente (Bunge, 1985), Mario Bunge formula una caracterización de la ciencia y de la tecnología, y de sus semejanzas y diferencias, que me parece convincente. Aquí me limitaré, por tanto, a recoger sintéticamente la distinción en cuestión y que sin más hago mía, lo que quizás pueda verse como el cumplimiento de un cierto deber de fidelidad, pues por debajo de la concepción que mantenía en la obra criticada por Vernengo estaba también -aunque quizás más implícita que explícitamente formuladala caracterización de la ciencia y de la tecnología elaborada por Bunge en otros trabajos suyos de fecha anterior (ver, sobre todo, Bunge, 1980).

El punto de partida del análisis de Bunge es que tanto las ciencias como las tecnologías (y también las ideologías, las pseudociencias, etc.) pueden verse como campos de conocimiento que comparten ciertas características, en el sentido de que en todos ellos se da:

1) una comunidad de sujetos que cultivan dicho campo (llamémosle C),

2) una sociedad anfitriona de $C$,

3) un dominio o universo del discurso de $\mathrm{C}$ : los objetos de estudio de $\mathrm{C}$,

4) una concepción general o filosofía inherente a $\mathrm{C}$,

5) un fondo formal: conjunto de herramientas lógicas o matemáticas utilizables en $\mathrm{C}$,

6) un fondo específico, o conjunto de supuestos que $\mathrm{C}$ toma de otros campos,

7) una problemática, o colección de problemas abordables en C,

8) un fondo específico de conocimiento acumulado por C,

9) unos objetivos o metas de C, y

10) una metódica o conjunto de métodos utilizables en $C$.

Aquí voy a prescindir de entrar en ningún detalle sobre las respectivas definiciones de ciencia y de tecnología propuestas por Bunge, para limitarme a mostrar qué es lo que, según este análisis, diferencia a ambos campos de conocimiento. Sintéticamente -y no exhaustivamente- tales diferencias podrían cifrarse en lo siguiente:

A) Las comunidades tecnológicas no son tan abiertas como las científicas: «las patentes y los secretos industriales y militares obstaculizan la difusión de los avances tecnológicos. El motivo es que, a diferencia del conocimiento científico, el tecnológico es una mercancía» (Bunge, 1985, p. 38).

B) La filosofía inherente a la tecnología se parece mucho al fondo filosófico de la ciencia básica (tanto la ciencia como la tecnología presuponen una ontología de cosas que cambian conforme a leyes y una gnoseología rea- 
lista) pero difiere de ésta en algunos aspectos: «Debido a su actitud práctica, el tecnólogo no se interesa tanto por las cosas en sí como por las cosas para nosotros: las que están o pueden estar bajo control humano (...). Puede darse el lujo de ignorar todo lo que no sea útil o utilizable. Es básicamente un pragmatista, aunque no adopte la filosofía pragmatista. Le interesa la verdad objetiva porque sabe que es útil, pero no le interesa como fin sino como medio para diseñar o planear» (Bunge, 1985, p. 38). Por otro lado, el ethos tecnológico difiere del científico en que aquel «no es el de la investigación libre y desinteresada al servicio de la humanidad, sino la de la tarea orientada a una meta práctica» (Ibíd.).

C) La problemática de la tecnología es tan rica como la de la ciencia, pero no consiste únicamente en problemas cognoscitivos, sino también en problemas prácticos.

D) Los objetivos de la ciencia incluyen el descubrimiento o uso de leyes, la sistematización en teorías de hipótesis y el refinamiento de métodos. En el caso de la tecnología, entre los objetivos esta «la invención de nuevos artefactos [entendida la expresión «artefacto» en su sentido más amplio de objeto artificial, esto es, «toda cosa, estado o proceso controlado o hecho deliberadamente con ayuda de algún conocimiento aprendido y utilizable por otros» (Ibid., pp. 33-4)], nuevas maneras de usar o adaptar los viejos y planes para realizarlos, mantenerlos y manejarlos, así como evaluarlos» (Ibid., p. 36).

E) La metódica de las tecnologías incluye tanto el método científico (problema cognoscitivo-hipótesis-contrastación-corrección de la hipótesis o reformulación del problema) como el método tecnológico (problema prácticodiseño-prototipo-prueba-corrección del diseño o reformulación del problema).

F) Las tecnologías tienen un componente del que carecen las ciencias, a saber, un conjunto de «juicios de valor acerca de cosas o procesos naturales o artificiales, en particular materias primas y productos manufacturados, procesos de trabajo y organizaciones sociotécnica» (Ibid., pp. 36-7) que se formulan a la luz de las metas u objetivos y de conocimientos científicos o tecnológicos. Bunge pone los siguientes ejemplos: «Esa catarata puede servir para activar un generador eléctrico». «Esta usina hidroeléctrica es buena para esta comunidad».

Además de estos rasgos distintivos con respecto a las ciencias, interesa destacar otras dos características de las tecnologías:

G) «A diferencia de la técnica tradicional, la tecnología moderna posee un voluminoso fondo formal y un voluminoso fondo específico (...) toda tecnología se funda sobre una o más ciencias» (Ibid., p. 39).

H) Los miembros que componen el campo de la tecnología -al igual que en el caso de la ciencia- «cambian, aunque sea lentamente, como resultado de investigaciones y desarrollos en $\mathrm{T}$ [en la tecnología de que se trate], así como en ciencias y tecnologías relacionadas con ella» (Ibid., p. 37).

4.2. Antes de entrar a considerar hasta qué punto las anteriores características pueden predicarse de la dogmática jurídica, quisiera hacer un par de consideraciones generales. La primera es que, a pesar de que el análisis de Bunge pretende tener un alcance general, me parece que el mismo está efectuado pensando más en las tecnologías basadas en ciencias naturales, que en las tecnologías o en las técnicas sociales. Ello plantea algún que otro 
problema en relación con la dogmática jurídica que he resuelto -o he tratado de resolver- interpretando con cierta libertad los planteamientos de Bunge. Pero no cabe duda de que en la dogmática jurídica los aspectos políticos y morales tienen una gran importancia que quizás no quede del todo reflejada en el esquema aquí utilizado. La segunda consideración previa es que, como se sabe, el carácter dogmático de la Jurisprudencia es entendido usualmente en el sentido de que la actividad desarrollada por los dogmáticos no es una investigación libre como la de la ciencia -o como la de las otras ciencias- sino que está limitada por las normas vigentes que funcionarían precisamente como dogmas. Esto es, en líneas generales, cierto, pero para mí está claro que la «vinculación a las normas» de la Jurisprudencia no tiene por qué interpretarse negativamente -pues verdaderamente cumple una función de gran trascendencia social-, no debe llevar tampoco a aproximar excesivamente esta actividad a la de la teología dogmática -pues los dogmas, las normas, en la Jurisprudencia, son esencialmente mutables-, ni a pensar que, por contraste con lo que ocurre en este campo, en el de la ciencia el dogma no juega ningún papel (Véase Atienza, 1985, pp. 282-3).

A') Pasando ya a la primera de las notas diferenciales, me parece innegable que las comunidades de cultivadores de dogmática jurídica son menos abiertas que las de los científicos, incluidos los científicos cuyo objeto de reflexión es también -en todo o en parte- el Derecho, como pudiera ser el caso de los sociólogos del Derecho o de los lógicos deónticos. Creo que podría decirse que lo que obstaculiza la difusión de los «avances» dogmáticos es, sobre todo, el carácter fuertemente nacional de la Jurisprudencia de las distintas dogmáticas- lo cual, obviamente, no significa afirmar que una obra de dogmática carezca absolutamente de valor más allá de las fronteras de un cierto sistema jurídico nacional: piénsese en el caso del Derecho internacional, en el de la dogmática alemana del XIX y del XX, cuya difusión, por otro lado, se restringió a los países dotados de un sistema jurídico perteneciente a la misma «familia» que el Derecho alemán, o incluso en la utilización del Derecho comparado (como se verá más adelante) en el «contexto de descubrimiento» de nuevas soluciones dogmáticas. Pero el conocimiento dogmático es, en razón de su propio objeto, un conocimiento relativamente cerrado, al igual que son cerradas las comunidades de los dogmáticos (difícilmente cabría hablar, por ejemplo, de congresos mundiales de dogmática jurídica) y con una (relativamente) escasa capacidad expansiva. Los avances o las soluciones ofrecidas por la dogmática sólo lo son en relación con un determinado texto, naturalmente susceptible de ser cambiado, que se enmarca dentro de una cierta configuración normativa, un cierto orden de valores, etc.

Por otro lado, el producto de la dogmática puede ser considerado frecuentemente como una mercancía, pero que posee características distintas a las de las «mercancías tecnológicas». En efecto, las soluciones elaboradas por los dogmáticos -si son soluciones adecuadas, es decir, si resuelven en términos satisfactorios para algún operador jurídico (incluidos los particulares) problemas de interpretación, aplicación y mejora de las normas- están en la base de actividades de asesoramiento que tienen un valor en el mercado, es decir, que son traducibles en términos económicos con independencia de que sean o no los propios dogmáticos (en cuanto operan también co- 
mo prácticos del Derecho) quienes desarrollen estas actividades; aquí es pertinente la distinción establecida por Vernengo entre técnicas en cuanto «repertorio de actividades orientadas a lograr ciertos fines» y técnicas como «conjunto de enunciados legales cuya aplicación o realización pretenda alcanzarse con esas actividades» (Vernengo, 1986), aunque me parece que esa distinción no es tan clara en el Derecho (en donde el dogmático es también muchas veces un práctico del Derecho) como en otros campos (en los que la «división del trabajo» es más estricta). En todo caso, el conocimiento dogmático es, por su propia naturaleza, un conocimiento público que no puede mantenerse en secreto, pues su objetivo es el de servir de orientación a los órganos encargados de interpretar, aplicar o elaborar el Derecho. La obtención de cierto consenso por parte de la comunidad jurídica es una condición necesaria, e incluso cabría discutir si también suficiente (Véase Aarnio, 1983 y Ruiz Manero, 1985), para la definición de «solución dogmática».

B') En cuanto a la filosofía inherente a la dogmática, lo dicho por Bunge a propósito del tecnólogo puede aplicarse sin más a quien opera en el campo de la Jurisprudencia. Es cierto que a lo largo de su dilatada historia se han sucedido concepciones distintas de la Jurisprudencia conectadas con muy diversas tradiciones filosóficas. Pero no creo que nadie pueda poner en duda que quienes se han dedicado al cultivo de la Jurisprudencia (desde los juristas romanos a los «dogmáticos» del XIX y del XX, incluyendo a quienes -como los juristas marxistas- han propuesto modelos «alternativos» al de la «ciencia» jurídica tradicional) han defendido básicamente una concepción pragmática del saber -de su saber- que les ha llevado a sentir -profesionalmente hablando- respulsión hacia toda aquella especulación que no llevara, en forma más o menos inmediata, a resultados prácticos. Podrían ponerse muchos ejemplos de ello, pero creo que la desenfadada inteligente y a veces acerba crítica de Ihering a los juristas que habitan en «el cielo de los conceptos» sigue teniendo un valor paradigmático para los actuales cultivadores de la dogmática. No resisto la tentación de transcribir uno de los párrafos -entre muchísimos otros de análogo significado- de su famosa obra Bromas y veras en la Jurisprudencia, aunque me permito recordar de todas formas que lo que Ihering -que por algo ha sido uno de los mayores genios de la historia de la Jurisprudencia- pretendió combatir no fue «la orientación especulativa en sí, sino sus aberraciones» (Ihering, 1974 p. 52). He aquí el texto en cuestión: «iEscribir sobre derecho pasando por alto deliberadamente la aplicabilidad práctica de la materia es como construir un reloj poniendo gran empeño en su ornato, pero ningún cuidado en la marcha de su mecanismo! Ahí reside precisamente el mal: en que se convierta a la jurisprudencia en una especie de zoología, cuando es en realidad el arte de arar con los animales de tiro que nos proporciona el derecho» (Ibid., p. 27).

C') Pasando ahora a la cuestión de cuáles sean los problemas que puedan considerarse como característicos de la dogmática jurídica, me parece que la respuesta aquí no es tampoco dudosa. El dogmático del Derecho se plantea y pretende resolver esencialmente problemas de tipo práctico como el siguiente.

La Constitución española atribuye al Tribunal Constitucional la facultad de resolver recursos de amparo que puede interponer cualquier ciudada- 
no para recabar la tutela de las libertades y derechos reconocidos en los artículos 14 a 30 de dicho texto. Ahora bien, algunos de estos derechos fundamentales son de una enunciación tan general (piénsese, por ejemplo, en el derecho a la tutela efectiva del art. 24 o en el principio de igualdad ante la ley del art. 14) que existe el riego de ampliar en forma desmedida dicha competencia, convirtiendo al recurso de amparo en una especie de supercasación; con ello se desnaturalizaría tal institución y se impediría, de hecho, el buen funcionamiento del Tribunal, ante la práctica imposibilidad de hacer frente a esa enorme competencia. El problema es, pues, éste: ¿cómo «delimitar el ámbito del recurso constitucional de amparo respecto de las vías ordinarias de protección judicial» (García de Enterría, 1984, p. 138), de manera que se eviten las consecuencias negativas que se acaban de señalar y, al mismo tiempo, se respete tanto la Constitución como la Ley Orgánica del Tribunal Constitucional?

Ciertamente, frente al anterior ejemplo se podría objetar que los dogmáticos del Derecho se ocupan también de problemas de orden más abstracto y de naturaleza más cognoscitiva que práctica: valga como ejemplo la teoría del delito elaborada por la dogmática penal -especialmente por la alemanadesde mediados del XIX. Ahora bien, por un lado, cabe recordar que lo que caracteriza a la tecnología frente a la ciencia no es que la primera no se ocupa de problemas cognoscitivos, sino que no se ocupa sólo o preponderantemente de tal tipo de problemas. Por otro lado, es indudable que los límites entre la dogmática jurídica y la teoría general del Derecho son menos claros cuando se consideran cuestiones pertenecientes a la parte general, en particular a lo que Scarpelli llama «alta dogmática» (Scarpelli, 1983, p. 331 y ss.), que cuando se abordan problemas de la parte especial. Finalmente, conviene tener en cuenta que en el fondo de las más abstractas de las teorías de la dogmática suelen latir problemas prácticos, cuya solución es precisamente lo que justifica dicha teoretización: la posibilidad de incurrir en un «exceso de abstracción» es un riesgo que casi todos los dogmáticos tratan de conjurar. Pondré un par de ejemplos que considero son ilustrativos de lo que acabo de decir.

El primero de ellos lo proporciona el concepto de «acción» que hasta hace no mucho tiempo se suponía constituía el centro de gravedad de la teoría del delito. En los últimos años se ha producido en la dogmática penal una desvalorización de dicho concepto en favor del de «tipicidad» $\mathrm{o}$ «acción típica», y la razón es que se considera que el de «acción» no tiene en realidad una gran relevancia en la práctica: los tribunales y, en general, los prácticos del Derecho penal no tratan con «acciones en sí», sino con «acciones jurídicas», con acciones tipificadas por la ley; su problema no es el de determinar cuando existe una acción en general, sino el de determinar cuando una acción es típica -corresponde al modelo descrito en la norma- y puede, en consecuencia, ser constitutiva de delito (Cfr. Rodríguez Mouru1lo, 1978 p. 221).

Otro ejemplo interesante lo proporciona la discusión en torno al concepto de delito desarrollada en el marco de la dogmática penal española y que dio lugar a una «notable disputa doctrinal» (Cobo-Vives, 1984, p. 224) que giró en tomo a cómo debía entenderse el término «voluntarias» que aparecía en la definición legal de delito del párrafo primero del artículo 1 del 
Código penal: «son delitos o faltas las acciones u omisiones voluntarias penadas por la ley». Hoy, la disputa en cuestión, que ocupaba diversas páginas de los tratados de parte general de Derecho penal, está desapareciendo -al menos en las obras «puestas al día»- como consecuencia de la entrada en vigor de la Ley 8/83, de 25 de junio que ha sustituido el término «voluntarias» por el de «dolosas o culposas». Esto último prueba (además de la capacidad de la dogmática para inducir cambios en el Derecho) que el problema en cuestión no lo era de carácter cognoscitivo (no se trataba de elaborar hipótesis y teorías acerca de qué pudiera ver la voluntad) sino de naturaleza práctica (se trataba de ofrecer una interpretación de «voluntarias» que permitiera una aplicación razonable de dicho artículo; así, por ejemplo, la mayoría de la doctrina rechazaba que «voluntarias» se interpretara en el sentido de «maliciosas» pues, en tal caso, la definición en cuestión sólo lo sería de los delitos dolosos -no de los culposos-, el párrafo segundo de dicho artículo - «las acciones y omisiones penadas por la Ley se reputan siempre voluntarias, a no ser que conste lo contrario»- habría que entender que establecía una presunción de malicia, etc. [Véase Cobo-Vives, 1981, pp. 30 y ss.]).

D') Los objetivos o funciones que desarrolla la dogmática jurídica creo que pueden reducirse, como lo señalaba en mi libro (Atienza, 1985, p. 277), a las de suministrar criterios para la aplicación del Derecho vigente y para el cambio del Derecho en las diversas instancias en que éste tiene lugar, y a la de elaborar un sistema conceptual con vistas a conseguir los dos anteriores objetivos. Dicho de otra manera, la finalidad de la dogmática es la de controlar -o contribuir a controlar- los procesos de interpretación, aplicación, desarrollo y cambio del Derecho, para lo cual, naturalmente, el dogmático construye, adopta o reformula conceptos, métodos y teorías. Provisto de tales instrumentos, el dogmático realiza una labor de sistematización y descripción del Derecho vigente que, sin embargo, no me parece que pueda entenderse como un objetivo último de la dogmática (aunque el hábito de contemplar al dogmático del Derecho en cuanto docente pudiera hacerlo creer); la transmisión de conocimientos y la descripción ordenada de un cierto sector del ordenamiento jurídico son funciones subordinadas o, si se quiere decirlo de otra manera, constituyen el punto de partida o una meta intermedia de la elaboración dogmática, pero no su punto de llegada, su objetivo final. Por otro lado, y aunque no pueda entrar aquí en detalles sobre ello, me parece que entre las «teorías dogmáticas» y las «teorías científicas» (o entre las «descripciones dogmáticas»-del Derecho vigente- y las «explicaciones científicas») hay una indudable analogía, pero no creo que dicha analogía pudiera proseguirse más allá de un cierto punto.

E') Volveré ahora de nuevo al problema relativo a los límites del recurso de amparo en nuestro ordenamiento jurídico para ilustrar cuál es -según creo- el método característico de la dogmática. La forma de proceder de un dogmático solvente y cuyos trabajos gozan de prestigio indiscutido entre los otros cultivadores de la dogmática, cuando aborda el tema en cuestión, nos puede servir para reconstruir dicho método (Cfr. García de Enterría, 1984).

Tal forma de proceder podría esquematizarse a partir de los siguientes pasos. 1) En primer lugar, se plantea el problema en los términos que ya 
nos son conocidos. 2) Luego, se reconstruye el modelo de solución que hasta la fecha parece haber guiado al Tribunal Constitucional y que consiste, básicamente, en distinguir entre cuestiones de Derecho constitucional (propias del alto Tribunal) y cuestiones de Derecho ordinario o no constitucional (reservadas a los jueces y tribunales ordinarios). 3) Ahora bien, semejante distinción (y otras análogas utilizadas también por el tribunal o en que pudiera pensarse acudiendo al Derecho comparado o bien a la Constitución y a la Ley Orgánica del Tribunal) resulta insatisfactoria, ya que tiene un alcance puramente formal y lleva, en consecuencia, a soluciones formalistas. 4) Para justificar lo anterior se acude al siguiente ejemplo. Hay cuestiones, como es el caso de la ejecución de las sentencias contencioso-administrativas, que son de pura legalidad ordinaria, pero que obstaculizan el ejercicio de los derechos fundamentales susceptibles de amparo (en particular, el derecho a la tutela judicial efectiva del art. 24 de la Constitución). Si el Tribunal Constitucional operase -y eso es lo que parece haber hecho hasta la fechacon el criterio indicado, entonces no se podría alcanzar de hecho una tutela efectiva del derecho fundamental por el que se reconoce el amparo. El Tribunal se limita, en efecto (cuando reconoce el amparo) a requerir a los tribunales contencioso-administrativos para que ejerciten sus facultades en orden a alcanzar la ejecución de sus sentencias, pero no entra en la cuestión (que sería ya de administración ordinaria de la justicia) de cuales sean los obstáculos legales que hacen que las facultades de tales tribunales en esa materia carezcan de eficacia en la práctica (la Administración -y no los jueceses, según la legislación preconstitucional no derogada expresamente, competente para la ejecución de las sentencias que la afectan). 5) Finalmente, inspirándose en las soluciones dadas, para casos análogos, por el Tribunal Constitucional alemán y el Tribunal Supremo estadounidense, se diseña una posible solución que permitiría resolver el problema y que además estaría en conformidad con la Constitución (con los valores materiales de la Constitución) y con la Ley Orgánica del Tribunal Constitucional. Según ella, el Tribunal Constitucional debería «concentrarse en la resolución de las grandes cuestiones, que afectan a las directrices generales del ordenamiento y, en particular, a la efectividad de los valores constitucionales, en nuestro caso de los derechos fundamentales» (García de Enterría, 1984, p. 158). De esta manera se conseguiría, por un lado, que el Tribunal Constitucional interviniera también cuando «esa legalidad y esa actuación judicial ordinaria no reflejasen esos valores y mucho más si los hiciesen obstáculos» (Ibid.), y, por otro lado, puesto que el Tribunal podría imponer criterios efectivos para la actuación posterior judicial (de los jueces ordinarios), aquél «no tendría por qué perder tiempo en insistir de nuevo en casos idénticos» (Ibid., p. 159), de manera que se lograría también evitar que un exceso de competencias paralizase -o al menos hiciera extremadamente lenta- la actividad del Tribunal.

Sin necesidad de entrar en mayores detalles, creo que puede aceptarse que tal modo de proceder está mucho más cerca de lo que Bunge llamaba método tecnológico que del método científico.

F") Tampoco parece discutible afirmar que, en la actividad del dogmático del Derecho, determinados juicios de valor, de significado análogo a los que Bunge consideraba como característicos de las tecnologías, juegan 
un papel esencial, particularmente en el proceso de evaluación de las soluciones dogmáticas. Así, una cierta propuesta de solución se considerará adecuada -y podrá lograr consenso en la comunidad de los dogmáticos y de los juristas en general- si «promueve o al menos no pone en riesgo la seguridad jurídica», «respeta y desarrolla los valores constitucionales», «garantiza una protección real y efectiva de determinado derecho fundamental», etcétera.

Si pasamos ahora -y para terminar ya con este apartado- a considerar las características de las tecnologías anteriormente indicadas con las letras G) y H), la conclusión a que creo hay que llegar es que -por el contrario de lo que ocurría con las otras características precedentes- la dogmática jurídica no parece satisfacer esos dos requisitos. La dogmática jurídica mantiene pocas, y poco profundas, relaciones con la ciencia y, desde luego, no me parece que pueda decirse que se base en alguna(s) ciencia(s) en particular, sino más bien en una combinación de experiencia, sentido común, conocimiento ordinario, etc. Quizás por ello se haya mantenido -y se mantenga- llamativamente al margen de los procesos de cambio que tienen lugar en la ciencia y en la tecnología: «El modelo cognoscitivo del saber que cultivamos- ha escrito un jurista que se ha planteado con frecuencia los problemas epistemológicos de la «ciencia» jurídica- sigue siendo sensiblemente igual al que se constituyó hace cerca de dos siglos. No se han producido transformaciones similares a las alcanzadas en otras áreas del conocimiento dentro de las propias ciencias sociales» (Hernández Gil, 1981, pp. 19-20). En resumen, la situación actual de la Jurisprudencia contrasta fuertemente (para emplear un término de comparación utilizado con cierta frecuencia) con la de la Medicina, en cuanto técnica que, a partir de comienzos del XIX y cada vez de manera más acusada, se basó en los conocimientos procedentes de la química, de la biología, etc. Esa es la razón de que en mi libro de Introducción al Derecho considerase a la dogmática jurídica -en su estadio actual- como un tipo de saber más próximo a las técnicas tradicionales que a las tecnologías (es decir, a las técnicas que se basan en conocimiento científico).

4.3. Y llegamos por fin a la cuestión de si tiene algún sentido seguir discutiendo acerca del «status epistemológico» de la Jurisprudencia. Mi opinión al respecto es que si la pregunta «¿es científica la Jurisprudencia?» se plantea sencillamente como una especie de test para medir el mayor o menor prestigio de que ha de gozar una determinada actividad y la comunidad de quienes profesionalmente la desarrollan, entonces la respuesta -cualquiera que ésta sea- carece de relevancia teórica y quizás no tenga tampoco mucha importancia práctica, pues no es de esperar -como indica Vernengo al comienzo de su comentario- que los dogmáticos vayan a modificar, por el simple hecho de que su actividad se considere o no «científica», la forma de cultivar su disciplina. Semejante debate no parece cumplir más que una función ideológica (que, de todas formas, tampoco conviene olvidar): la de descalificar o justificar, según los casos, el saber jurídico tradicional, pero sin que nuestro conocimiento sobre el mismo se vea aumentado por ello (Cfr. Calsamiglia, 1986).

Creo, sin embargo, que hay otra manera de abordar la cuestión que sí puede resultar fructífera. Consiste en partir de una reconstrucción, en el marco 
de la cultura contemporánea, del concepto de ciencia y de tecnología (y, eventualmente, también del de ideología, pseudociencia, etc.) y usarlos como modelos que nos permitan conocer mejor lo que sea el proceder dogmático y, eventualmente, proponer líneas para su modificación o desarrollo. Concretamente, a partir del análisis efectuado en el anterior apartado se podrían extraer, en mi opinión, algunas conclusiones de interés.

La primera es que si la actividad dogmática obedece más al modelo de proceder técnico que al científico, entonces los filósofos y teóricos del Derecho que reflexionan sobre el saber jurídico tradicional deberían trasladar su centro de interés desde el campo de la filosofía de la ciencia (lo que no quiere decir tampoco que debieran abandonar completamente éste) al de la filosofía de la técnica. En particular, creo que debería prestarse mucha mayor atención de lo que suele hacerse al propio concepto de técnica y, sobre todo, al de técnica social que muchas veces pasa casi desapercibido a los teóricos de la técnica (Cfr., por ejemplo, Rapp, 1981).

La segunda conclusión -y con ello insisto en algo que trataba de señalar en mi libro de Introducción al Derecho- es que la vieja disputa sobre el carácter científico o no de la Jurisprudencia es seguramente un problema mal planteado y que debiera ser sustituido por este otro o, si se quiere, que debiera ser replanteado en los siguientes -o parecidos- términos: ¿Debe la dogmática seguir siendo cultivada a la manera tradicional o podría también aquí darse el paso de la técnica a la tecnología como ocurrió con la Medicina? ¿Bajo qué condiciones podría tener lugar dicho cambio y con qué efectos? ¿Qué disciplinas podrían prestarle a la Jurisprudencia una sólida base científica?, etc.

La tercera es que una conciencia más clara por parte de los dogmáticos de cual sea la naturaleza, los objetivos, etc. de su actividad podría tener un efecto beneficioso sobre su propio trabajo. Así, la comprensión de que lo que se cultiva es un tipo de saber técnico podría evitarles abordar investigaciones pseudocientíficas de más que dudoso resultado. Un buen ejemplo de ello es la persecución de naturalezas jurídicas que sigue ocupando una porción considerable del tiempo de los juristas teóricos. Está claro que lo que empuja a los juristas a proseguir una búsqueda tan infructuosa es su desconocimiento de la filosofía del lenguaje de este siglo, pero también el plantearse como un problema cognoscitivo lo que es una cuestión de carácter práctico, de carácter técnico. Visto de esta última manera, el problema (ciertamente interesante) consiste en tratar de «procurarse una guía para resolver casos cuya solución no puede extraerse de las normas del sistema», mediante el expediente de «emparentar a instituciones de aparición reciente con otras de ilustre linaje» (Carrió, pp. 8 y 9).

Y la cuarta conclusión es que todo lo anterior no debe entenderse como un llamamiento a los dogmáticos del Derecho para que den la espalda a la ciencia. De lo que se trataría es de que sus relaciones con la ciencia fueran otras -más sanas, creo yo- de lo que suelen ser: la función del cultivador de la dogmática no es hacer ciencia, sino utilizar el conocimiento científico (y tecnológico) disponible para construir soluciones más adecuadas. 


\section{5}

Termino indicando sintéticamente -y como resumen en cierto modo de todo lo anterior- cuales creo yo que son las discrepancias y las coincidencias que tengo con Vernengo a propósito del tema (o de los temas) aquí debatido(s). Para facilitar su posible discusión los enumeraré en seis puntos.

1. La exposición que Vernengo efectúa de mi concepción sobre la dogmática jurídica -por las razones ya indicadas- no me parece que refleje con exactitud mi punto de vista.

2. No veo por qué ha de ser inadecuado ofrecer a los estudiantes que se inician en el estudio del Derecho una visión de la dogmática jurídica como una técnica socialmente útil -aunque necesitada de transformaciones seguramente profundas-, que se caracteriza ademas por ser un saber normativo y valorativo -o, si se quiere, político- en el sentido débil antes indicado. Lo que consideraría inadecuado, y creo haber aclarado las razones de ello, es presentar a la Jurisprudencia como un saber de carácter semejante o equiparable a aquéllos para los que suele utilizarse la expresión «ciencia»

3 . Vernengo opone a mi tesis de que la Jurisprudencia -en su estadio actual- es esencialmente una técnica, el hecho de que los juristas desarrollan actividades de distinto tipo, «algunas de las cuales no hay inconveniente en caracterizar como científicas y en denominar «ciencia» a su formulación» (Vernengo, 1986). Lo que a mí me gustaría saber es cuáles son esas actividades presuntamente científicas y qué peso tienen en el conjunto de la actividad dogmática.

4. Estoy de acuerdo con Vernengo en que la de la dogmática es una actividad heterogénea, pero creo que por encima de su diversidad existe algo en común que une a todas las actuaciones dogmáticas, a saber, el estar encaminadas todas ellas hacia la realización de una finalidad práctica; en definitiva, el integrar una técnica social de carácter complejo. Si no me equivoco, el propio Vernengo apunta a ello al final de su comentario: «iSe parece más el jurista al político en trance de tomar una decisión a la luz de cierta valoración o de cierta ideología, o semeja más al psicólogo en su práctica clínica? ¿O cabe compararlo con científicos como el sociólogo o el historiador terrenos teóricos indisputados pero donde la actividad experimental o la práctica clínica son inexistentes? La respuesta es obvia: algunas de las cosas que hace el jurista lo asemejan al político; otras lo acercan al ingeniero, al médico, al psicólogo [ejemplos todos ellos de técnicas] ¿Por qué poner todo bajo un único rasero?» (Vernengo, 1986).

5. Vernengo me acusa de haber sostenido que los juristas sólo pueden relacionarse con las ciencias «en la medida en que recurrieran a ese pot-pourri (lógica, sociología, economía, teoría de juegos, etc.)». En su opinión «los juristas del presente y los de ayer, sean técnicos científicos o chamanes iluminados, no trabajan de ese modo ecléctico...» (Vernengo, 1986). En relación con este punto quisiera hacer dos observaciones. La primera es que yo no afirmé que los dogmáticos de hecho trabajen así, sino que planteaba la posibilidad de modificar la forma habitual de elaboración dogmática para incorporar y utilizar conocimiento científico y tecnológico proveniente de otras áreas distintas a la de la Jurisprudencia; es decir, mi afirmación no se situaba en el nivel de la metajurisprudencia descriptiva, sino en el de la 
metajurisprudencia prescriptiva. La segunda observación es que el propio Vernengo (en el texto transcrito en el punto 4 de este apartado y en otras partes de su comentario) parece incurrir en el mismo pot-pourri o eclecticismo, en relación con el modo de proceder dogmático, que a mí me atribuye. En descargo de Vernengo -y en el mío propio- cabría decir que tal planteamiento es inevitable cuando la cuestión de qué sea o qué deba ser la dogmática se afronta desde una perspectiva general.

6. Reflexionando sobre los anteriores puntos de este apartado, creo que habría base para afirmar que, en gran medida, nuestro desacuerdo es más un desacuerdo en cuanto a nuestras respectivas actitudes frente a la dogmática, que un desacuerdo de creencias sobre lo que sea la actividad dogmática (a las coincidencias anteriores añado ahora la de que también Vernengo está de acuerdo en que «muchas de las técnicas utilizadas por los juristas no tienen el carácter de una técnica científica, manteniéndose al nivel de prácticas más primitivas»). Me parece que esa diversa actitud podría expresarse así: Vernengo tiene una opinión más positiva que la mía (aunque la suya no implique una aceptación sin reservas ni la mía una crítica radical) acerca del modo de proceder del jurista dogmático. Para él se trata, a la manera weberiana, de un modo de proceder modélicamente racional (Cfr., por ejemplo Vernengo, 1984) que puede ser cambiado, pero siempre y cuando no se altere con ello el modelo en cuanto tal; supongo que esa es la razón de que vea una proclividad al irracionalismo en quienes ponen en cuestión el modelo vigente de dogmática y proponen su sustitución por otro distinto. Yo no considero, desde luego, que el proceder dogmático sea un proceder irracional pero estimo que, frecuentemente, no alcanza los niveles de racionalidad a que cabría aspirar dado el estado de desarrollo actual de las ciencias y de las tecnologías. Precisamente por eso considero interesante y pertinente porponer modelos alternativos al paradigma de la dogmática actualmente vigente.

\section{BIBLIOGRAFÍA}

Aarnio, A., Philosophical Perspectives in Jurisprudence, Acta Philosophica Fennica, Helsinki, 1983.

Atienza, M., Introducción al Derecho, Barcanova, Barcelona, 1985.

Bunge, M., Epistemología, Ariel, Barcelona-Caracas-México, 1980.

Bunge, M., Seudociencia e ideología, Alianza Universidad, Madrid, 1985.

Calsamiglia, A., Introducción a la ciencia jurídica, Ariel, Barcelona, 1986.

Carrió, G., Prólogo a E. Bulygin, Naturaleza jurídica de la letra de cambio, Abeledo-Perrot, Buenos Aires, 1961.

Cobo, M. y Vives, T., Derecho penal. Parte general, II, Universidad de Valencia, 1981.

Cobo, M. y Vives, T., Derecho penal. Parte general, Universidad de Valencia, 1984.

García de Enterría, E., Reflexiones sobre la ley y los principios generales del Derecho, Civitas, Madrid, 1984.

Hernández Gil, A., La ciencia jurídica tradicional y su transformación, Civitas, Madrid, 1981. 
Ihering, R., Bromas y veras en la Jurisprudencia (trad. de T. A. Banzhaf), Ejea, Buenos Aires, 1974.

Rapp, F., Filosofía analítica de la técnica (trad. E. Garzón Valdés), Alfa, Barcelona, 1981.

Rodríguez Mourullo, G., Derecho penal. Parte general, Civitas, Madrid, 1978.

Ruiz Manero, J., Consenso y rendimiento como criterios de evaluación en la dogmática jurídica. (En torno a algunos trabajos de A. Aarnio), en «Doxa. Cuadernos de Filosofía del Derecho», n. ${ }^{\circ}$ 2, Universidad de Alicante, 1985, pp. 209-222.

Scarpelli, U., La teoria generale del diritto: prospettive per un trattato, en La teoria generale del diritto. Problemi e tendenze attuali (Studi dedicati a Norberto Bobbio), ed. preparada por U. Scarpelli, Ed. di Comunità, Milán, 1983, pp. 281-340.

Vernengo, R., Racionalidad y conocimiento científico en la Jurisprudencia, en R. Vernengo y U. Schmill, Pureza metódica y racionalidad en la teoría del Derecho (Tres ensayos sobre Kelsen), UNAM, México, 1984.

Vernengo, R., Ciencia Jurídica o técnica política: ¿Es posible una ciencia del Derecho?, publicado en este mismo número de Doxa. 